\section{Research in France}

\section{All fonctionnaires now}

FROM the new year, all 12,000 French research council researchers and the 28,000 engineers (senior technicians), technicians and administrators who work with them will become civil servants, enjoying the security and pension rights dreamed of by every French man and woman. But fears that the 40,000 people concerned will now be bureaucratized, like the civil-servant scientists of Italy, are denied. According to Pierre Papon, director-general of the Centre National de la Recherche Scientifique (CNRS), on Monday, the move should "decrease the viscosity" of the French research system and be "a tool of science policy"'.

The new statute defining the admisssion and promotion of scientists and other ranks has been through $\mathbf{5 0}$ hours of roundtable negotiations and consultations and has emerged riddled with "derogations" - special exceptions that will distinguish it from the normal law of the civil service. For example, unlike the French civil service which can normally be entered only from the bottom grade, the new "research service" will have openings at every level, allowing senior scientists to be brought in from universities, industry or abroad and adding a horizontal dimension to the usual civil service verticality.

Such exceptions make the statute workable - but at the same time, the statute offers researchers lifetime employment from entry, at the age of 26-27, after completion of a thesis. This, the argument goes, should make for greater mobility as

\section{Research spending in OECD countries}
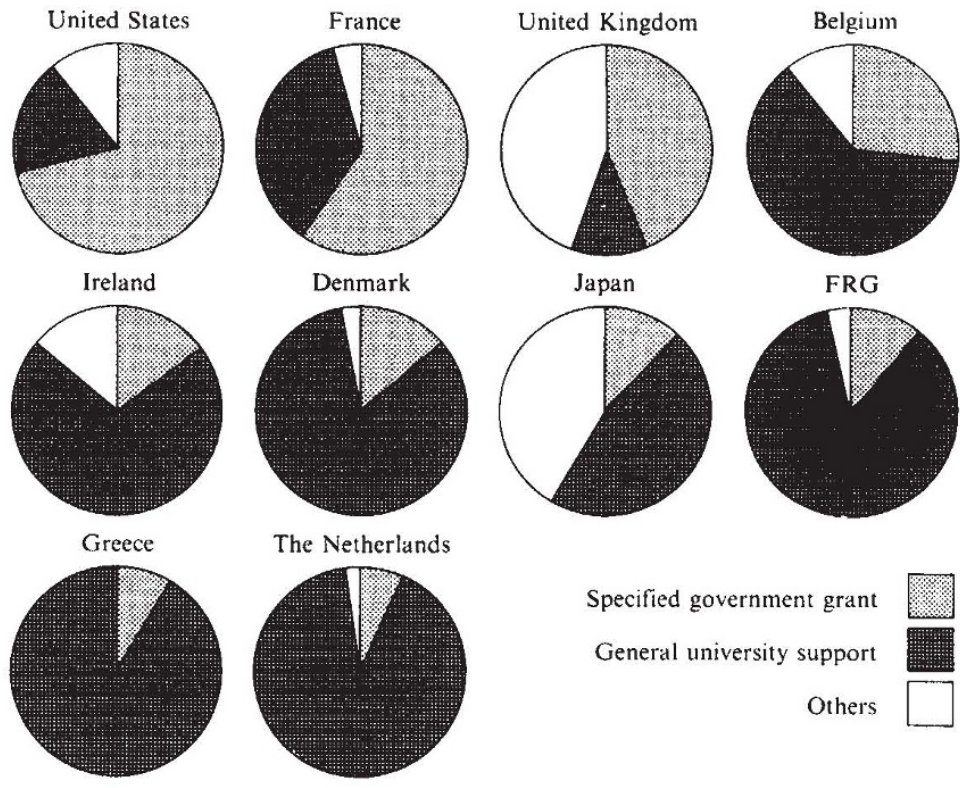

Denmark
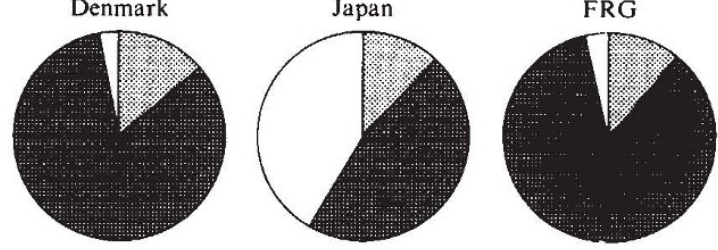

The Netherlands

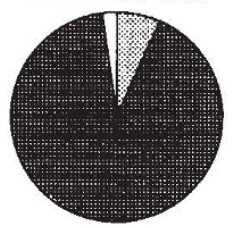

Specified government grant

General university support

Others

Specified government grant is defined as the money going to universities that is earmarked for research (such as that from the British research councils). General university support is an estimate sent in by each OECD country of how much of the total government grant is used for research and development. "Other" funds include those from industry, higher education itself and from other countries. sent, advancement in universities is less dependent on performance than on seniority, Kordon believes.

Some of the main points in the new statute are:

- Technicians may be promoted on the basis of work, not age; previously only age counted, and a survey last year at CNRS showed that up to half of CNRS technicians were under-graded as a result.

- Apart from job security, there are positive incentives to mobility, such as an extra salary step for a change of job and the consideration of breadth of experience in the appointment of directors of research. It will be possible to move into industry for a few years, for example, and then to return to one's job, to another research institution, to a university or to go abroad.

- The objective of a research career is broadened, to include training (of research students, for example), popularization and application of results (such as the deposition of patents). These will be taken into account during the interviews and publication reviews that lead to promotion.

- A very successful person can change corps - for example from technician to engineer, or secretary to administrative grade.

The new statute has some defects, however. Kordon emphasizes his use of the word "symbolic" and says that it may take technicians 12 years and scientists 6-10 years before they come to their first evaluation, so that the incentive is not high. Moreover, the commissions that will determine an individual's salary increments will include no scientists, only union and administrative people. "The coupling between a career and evaluation is too loose", says Kordon.

Indeed, the idea of accelerated promotion based on performance could falter for lack of vacancies at higher levels. Most French researchers were recruited in the late 1960s and are now middle-aged and middle-ranking.

Kordon and his team recommended to the minister that he should adopt a "promotion policy" that would aim to smooth the demographic structure over a period of, say, 10 years, but this was rejected.

Papon is also concerned about the detailed application of the statute - which will be defined by separate detailed decree for each organization.

Exactly how to assess the performance of technicians and administrators, who outnumber scientists $2: 1$ and who change jobs more frequently, remains to be determined. The assessment will have to be local and often rather than national and annual, as for researchers, Papon believes. These and other difficulties have led to a 50-page draft decree for CNRS which will supplement the 250 articles of the statute itself. The decree could not be ready before March or April, Papon thinks, and will then have to be applied retrospectively.

Robert Walgate 